\title{
Business process re-enginering of tourism e-marketplace by engaging government, small medium enterprises and tourists
}

\author{
Kadek Cahya Dewi ${ }^{1}$, Ni Wayan Dewinta Ayuni ${ }^{2}$ \\ ${ }^{1}$ Department of Business, Politeknik Negeri Bali, Bukit Jimbaran, Kuta Selatan, Badung, Bali, Indonesia \\ ${ }^{2}$ Department of Accounting, Politeknik Negeri Bali, Bukit Jimbaran, Kuta Selatan, Badung, Bali, Indonesia
}

\section{Article Info \\ Article history: \\ Received Dec 1, 2020 \\ Revised Apr 26, 2021 \\ Accepted Jul 27, 2021}

\section{Keywords:}

Business process

Business process re-enginering

E-marketplace

Small medium enterprises

\begin{abstract}
Not all tourism actors in Indonesia had utilize the e-marketplace. Therefore, one of the Indonesian government's focus is to improve the tourism business process model through e-marketplace based system. The research purpose was to re-engineer the business process of tourism e-marketplace by engaging government, small medium enterprises (SMEs) and tourists. The research used the mixed method approach that conducted by modifying The McKinsey BPR methodology. As the result, this research adding two novel aspects to the previous research which are "role" and "activities". The new tourism emarketplace business model proposed three kinds of role, namely: (1) government, (2) SMEs, and (3) tourists. This model also introduced activities including catalogue, finance, inventory management, collaboration, order fulfilment and customization. The proposed model was implemented and can be found in http://gonusadua.com. TELOS feasibility study was conducted to evaluate the model and found the final score of 8.3. It can be concluded that this model was feasible to develop and provide benefits for the government, SMEs, as well as the tourist. Beside had a contribution in built a new model of tourism e-marketplace, the research had also constructed a new tourism emarketplace system with some improvements on the business model.
\end{abstract}

This is an open access article under the CC BY-SA license.

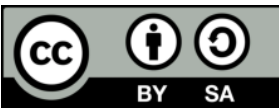

\section{Corresponding Author:}

Kadek Cahya Dewi

Department of Business

Politeknik Negeri Bali

Bukit Jimbaran, Kuta Selatan, Badung, Bali, Indonesia

Email: cahyadewi@pnb.ac.id

\section{INTRODUCTION}

The rapid development of the tourism industry has led to the inception of e-tourism, enabling potential tourists to make bookings and other related activities by online application [1]-[3]. The tourism sector's current population consists of millennial travellers familiar with information and communication technologies (ICT) based applications. E-tourism help tourism-related activities become accessible by tourists anywhere and anytime, i.e., before, during, and after travelling [4]. There are numerous advantages associated with the development of ICT applications in tourism, such as efficiency, touristic communication management and strategies, interoperability, personalization, marketing, and increased income [5]-[7]. Therefore, the application of ICT in the tourism sector is very important, especially amid COVID-19 pandemic.

The E-marketplace is one of ICT-based application that enables buyers and suppliers/sellers to unite in a platform, and also eliminates some of the inefficiencies in the supply chain [8]. The core service of emarketplace is to provide market space for the adequate conduction of e-commerce activities [9]. Previous 
research on e-marketplace was carried out in various sectors, such as product selling [10], manufacturing [11], inventory [12], procurement [13] as well as health and social care [14].

Although e-tourism has become popular and more familiar among users, many tourism destinations do not utilize this product. Nusa Dua Bali that is located in Indonesia is one of the popular destinations in Asia. According to previous research, some of the small medium enterprises (SMEs) had not familiar with the e-tourism applications [15]. It became a focus for the government in order to improve its capability as a popular tourism location. Currently, Nusa Dua Bali does not have its ICT-based application (e-marketplace) to simplify the SMEs of tourism activities to promote and sell their products or services. The government believe that if there was an e-marketplace that owned by the government, the SMEs around the area would be more interest in using the system. Therefore, the government of Nusa Dua Bali had planned to re-engineer the business process of tourism activities in Nusa Dua Bali to be e-marketplace based tourism, as their support to the SMEs.

The development of e-marketplace requires proper preparation and strategy, including reengineering the ongoing business processes. Business Process Re-engineering concept can fit and answer this problem. Business process re-engineering (BPR) is the analysis and design of workflows and processes within an organization [16]-[19]. A business process is a series of logically related tasks performed to achieve clear business results (aligned with the overall goals and vision of the business) [20].

There so many methodologies of BPR, one of them is The McKinsey BPR approach. Based on [21], McKinsey BPR approach has three steps, namely diagnostic, re-design and implementation. The McKinsey BPR approach does not have stages that diagnose potential users acceptance and system's owner development strategic. It also does not have a feasibility study stage to measure the feasibility of the product. This research needs to diagnose the acceptance of potential user and also diagnose the government strategies in re-engineering the business process. Furthermore, the product feasibility is also important to study on this research. This research needs to re-design the e-marketplace model to fit the problem of government role in the proposed e-marketplace, as the previous model on [9] had only two roles on the model which are seller and buyer. Therefore, the research problem is how the new business process of tourism e-marketplace by engaging government, SMEs and tourists. The research objective is to re-engineer the business process of tourism e-marketplace by engaging government, SMEs and tourists.

\section{RESEARCH METHOD}

The research object was the business process re-engineering of e-marketplace based tourism. The research was held from March 2019 until October 2020. This research took a case study in Nusa Dua (a popular tourism destination in Bali Indonesia). The research was using the mixed-method approach as shown in Figure 1. The research framework modified from The McKinsey BPR Methodology. The research framework fitted the gaps between the McKinsey methodology with the research problem. The research framework divided the McKinsey diagnostic stage into two stages namely: (1) acceptance diagnostic stage and (2) strategic diagnostic stage. McKinsey re-design stage renamed as modelling stage. Then after the McKinsey implementation stage, the research framework added feasibility study stage.

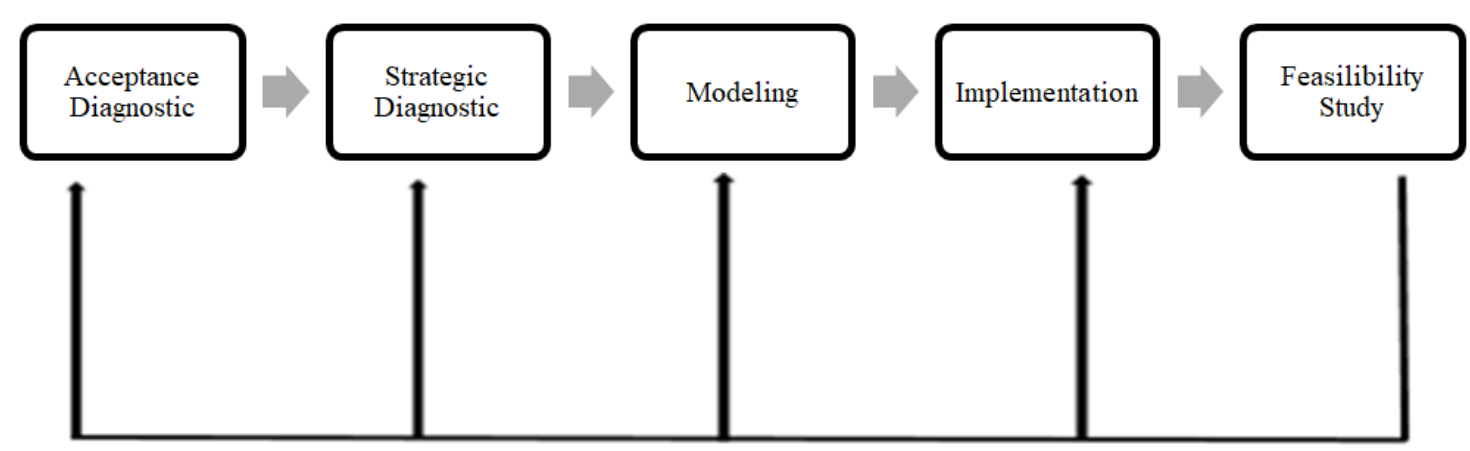

Figure 1. Research framework

Technology acceptance model (TAM) is one of the most popular research models used to address the process of user acceptance of information systems and technology [22]-[24]. The TAM model has been applied in various research fields, such as [23]-[29]. The inequality of ICT knowledge in SMEs, made the 
research consider the readiness, technology availability, and also computer self-efficacy issues. The acceptance diagnostic stage was carried out by the TARIM model using the quantitative approach, as shown in Figure 2. The TARIM model was a modified version of the conventional TAM and technology readiness index (TRI) by inserting the technology availability and computer self efficacy into the model. At this stage, data were collected from 100 SMEs in Nusa Dua using the questionnaire and analyzed with the structural equation model using partial least square method. The acceptance diagnostic was focused on SMEs acceptance of the ICT, specifically e-marketplace.

The strategic diagnostic stage was conducted by qualitative descriptive approach with data obtained through observation, in-depth interview and focus group discussion (FGD). The framework of strategies diagnostic as shown in Figure 3 was started by describing the strengths, weaknesses, opportunities and threats (SWOT) with technology readiness index (TRI) model consideration (SWOT-TRI). This was followed by mapping into external factor analysis strategy (EFAS) and internal factor analysis strategy (IFAS) matrix to obtain the government readiness position, which was used to design strategies in order to implement the BPR.

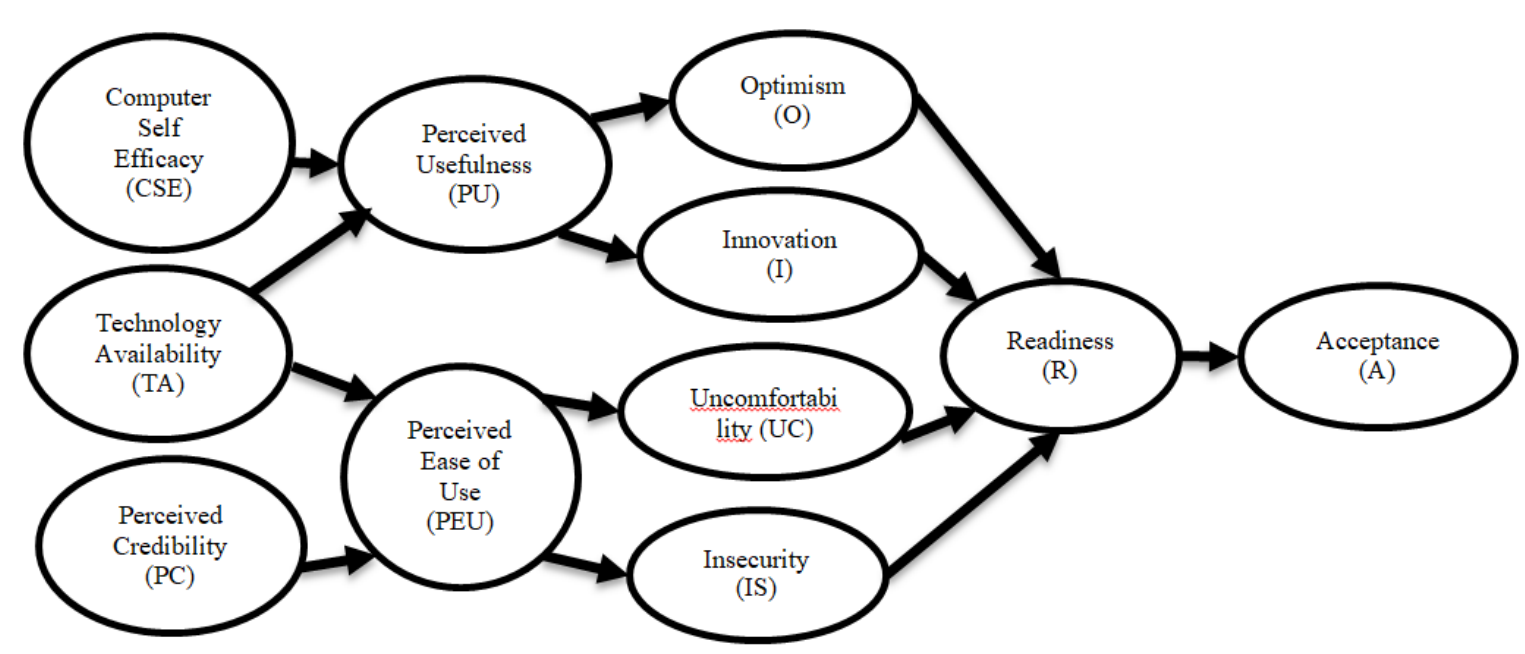

Figure 2. TARIM model

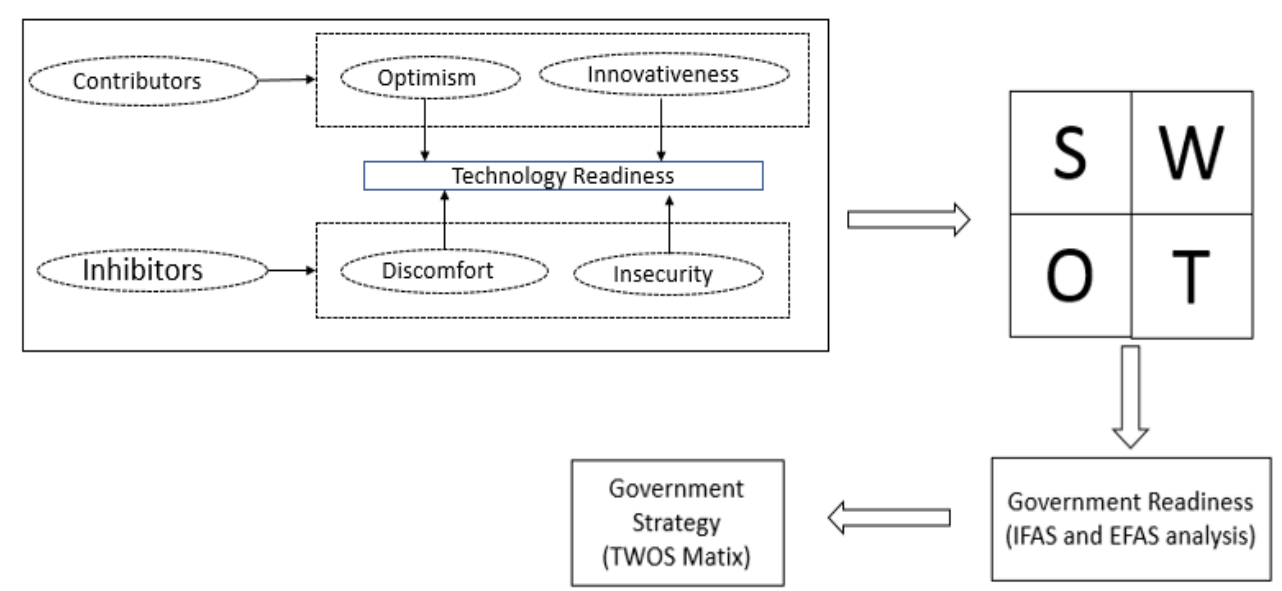

Figure 3. Strategic diagnostic model

The modelling stage was carried out depending on the result of the previous stage. The model validity was done by transferability, confirmability, credibility test and also dependability test. The transferability and credibility test were conducted by triangulation model that assessed the data with some 
different technics such as observation, in-depth interviews and also FGD. In order to do the confirmability and dependability test, the audit process was conducted by the experts.

The implementation stage was conducted by Agile development cycle approach with the SCRUM framework. The agile development cycle was chosen because Agile cycle could move quickly when change occurs [30]-[32]. The SCRUM framework bring an iterative and incremental approach to Agile methods [33].

The feasibility study was conducted as an evaluation of the implementation results. This process was carried out using the TELOS method that comprises of five dimensions, namely (1) technical, (2) economic, (3) legal, (4) operational, and (5) scheduling. The economic dimension was measured by cost-benefit analysis, while the operational dimension was determined by performance, information, economy, efficiency, and service (PIECES) analysis. Finally, the feasibility study result was validated by focus group discussion by developing an assessment rubric encompassing a scale such as very high (10) to very low (1) [34], [35].

\section{RESULTS AND DISCUSSION}

This section analyzes some data analysis results through the following processes (1) acceptance diagnostic, (2) strategic diagnostic, (3) modelling, (4) implementation, and (5) feasibility study.

\subsection{Acceptance diagnostic}

This stage was determining the factors that affect the acceptance of e-marketplace. Validity and reliability testing, evaluation of measurement model, evaluation of structural model and also hypotheses testing was done at this stage. The previous research said that TARIM was the novelty model of finding the factor that affecting SMEs acceptance of e-marketplace [36]. The result of this stage would be utilized as a consideration in proposed e-marketplace and also generate managerial implications. Based on the TARIM model, some main results of the research summarized are as shown in below:

- The factors affecting the acceptance of tourism e-marketplace in Nusa Dua Bali were technology availability and perceived usefulness. When people have adequate technology to run their business, they tend to accept the new process. This is in line with the previous research, that the availability of technology, using a computer, smartphone, and internet services, leads to the formation of positive attitudes toward technology [37]-[40]. This result also extends previous studies that technological factors, such as availability and usage, can contribute to e-business development in a nation [41], [42]. Furthermore, perceived usefulness ensured that people had adequate knowledge regarding the usefulness of e-marketplace in Nusa Dua Bali. This result is an extension of previous studies that perceived usefulness positively affected trust [43].

- Personality paradigm factors, such as optimism, innovation, uncomfortably, and insecurity, did not significantly impact the acceptance of tourism e-marketplace in Nusa Dua Bali as opposed to previous studies [44]-[47].

The result provides some managerial implications that have the ability to affect the strategies and modelling stages. The managerial implications that occur namely:

- A local entrepreneur can be involved as a user with the role of a "seller" in the e-marketplace

- $\quad$ The e-marketplace needs to be designed to run in a common technology, such as a browser.

- $\quad$ The e-marketplace needs to be designed for easy usage.

- $\quad$ The e-marketplace needs to have many features that support businesses.

\subsection{Strategic diagnostic}

This stage had a purpose for positioning government readiness in reengineering the business process of e-marketplace based tourism and then generated the government strategies. According to the SWOT-TRI analysis, government readiness was in a strong position to act as a provider of e-marketplace in Nusa Dua Bali. It was possible for them to carry out aggressive growth because they have the opportunities and strengths needed. The government growth oriented strategies namely:

- Utilizing existing internet connections maximally to develop e-marketplace to attract more IT-literate travelers.

- Take advantage of research collaboration opportunities to improve the staff's ability to manage emarketplace and digital marketing.

- Take advantage of research collaboration opportunities in the development of e-marketplace as a pilot project to cover the lack of human capabilities, availability of infrastructure, and funding problems.

- Actively involving the SMEs in the development of e-marketplace to make it easier in creating an SMEs database.

- $\quad$ Prepare a funding budget for sustainable e-marketplace development. 
- $\quad$ Use the existing popular e-marketplace as a benchmark to ensure that users do not need to adapt much during usage.

- Developing e-marketplaces by prioritizing data security and preparing special personnel to handle data security.

- Using a cloud server e-marketplace with data security facilities.

- Using outsourced personnel in developing and maintaining e-marketplaces

\subsection{Modeling}

The e-marketplace based tourism business model was designed based on the result obtained from previous stages, as shown in Figure 4. The model was adopted e-marketplace business model by [9]. The core services of tourism e-marketplace business model were to provide a market space where tourism activities transaction could be carried out. The e-marketplace also facilitated other e-business activities such as catalogue, finance, inventory management, collaboration, order fulfilment and customization. The role involved in this model were: (1) SMEs as a seller on the previous model [9], (2) Government as the new role designed on this model, and (3) Tourists as a buyer on the previous model [9]. The novel aspects as an improvement from the previous study were role and activities. The new model added government as a new role in the e-marketplace business model, as well as data centre and order fulfilment activities as the new processes. Data centre activity was designed for the government with purpose the government could manage all the SMEs data on their area, so they could generate any reports or made predictions of the tourism activities on their area. Order fulfilment activity was designed for tourists to make travelling easier. Besides the tourism e-marketplace business model, this stage also decided the website domain name and designed a product logo. The domain name was "gonusadua.com" which means "travelling to Nusa Dua".

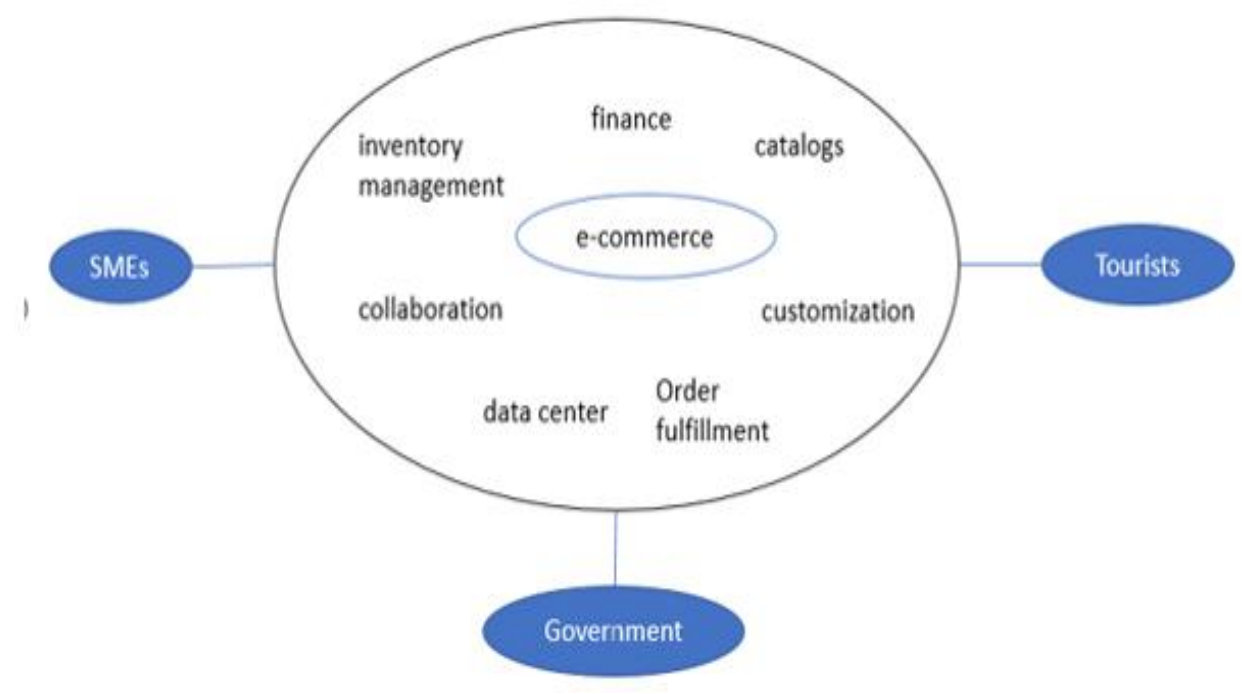

Figure 4. Tourism e-marketplace business model

The validation of the proposed model was conducted by triangulation technic that assessed the data by observation, in-depth interviews and FGD. The audit process was also conducted to the model as the validation process. The observation process was done in Nusa Dua Bali. The observation process is carried out by examining the proposed business processes/activities and the proposed roles by comparing them with the actual activities that were running. In-depth interviews were carried out with the government who will be the owners of this model. The results of observations and interviews indicate that the proposed model has met the needs. The next process was an FGD involving SMEs, tourists and the government. During the FGD, the FGD participants filled out a user acceptance test (UAT) form which validated the proposed model. The result of the FGD was that the participants agreed and stated that the model is valid to be implemented. Therefore, the triangulation model concluded that the proposed model was valid and agreed to be implemented. The audit process was conducted by the experts from Politeknik Negeri Bali and DRPM Kementerian Riset dan Teknologi/Badan Riset dan Inovasi Nasional Indonesia. The proposed model has been presented and got valid results. 


\subsection{Implementation}

Implementation stage built e-marketplace product according to the new business model as shown in Figure 4. The Agile cycle built backlog and sprint [30]-[33]. Sprint timeline consisted of five (5) sprints and took approximately seventy (70) days to develop gonusadua.com, as shown in Table 1. Each sprint had activities that consist of sprint planning, daily scrum, product development, sprint review dan sprint retrospective. Product development was done by own personalized framework. Scrum team consisted of one person as product owner, two persons as development team, and one person as scrum master.

Table 1. Sprint

\begin{tabular}{ccc}
\hline Name & Product Backlog & Days \\
\hline Sprint 1 & Web Front End & 14 \\
Sprint 2 & Web Back End & 14 \\
Sprint 3 & gonusadua.com for Government & 14 \\
Sprint 4 & gonusadua.com for SMEs & 14 \\
Sprint 5 & gonusadua.com for Tourists & 14 \\
& Total days & 70 \\
\hline
\end{tabular}

\subsection{Feasibility study}

As an evaluation stage of the implementation results, a feasibility study was carried out using the TELOS method with five feasibility dimensions, namely Technical, economic, legal, operational and schedule. Through these five dimensions of TELOS, the feasibility of the product can be assessed. In the technical dimension, data collection techniques are carried out through interviews and observations regarding the technical specifications of the product, namely http://gonusadua.com. The economic dimension is measured using a cost-benefit analysis. The legal dimension is measured based on copyright status. The operational dimensions are measured based on the PIECES analysis method, namely by comparing the dimensions of performance, information, economy, control, efficiency and services between the old business model and the new business model. The schedule dimension is measured based on the timeliness of the schedule.

Table 2 shows the score for each dimension of TELOS. Based on the analysis, the final score of the TELOS dimensions was the average of total TELOS score. Therefore, the product gonusadua.com that built from tourism e-marketplace business model got the final score of 8.3. Based on the assessment rubric that encompassing a scale such as very high (10) to very low (1), therefore it could be categorized as high or FEASIBLE to be implemented in a sustainable manner.

Table 2. TELOS analysis

\begin{tabular}{cl}
\hline Dimension & \multicolumn{1}{c}{ Description } \\
\hline Technical & $\begin{array}{l}\text { The required specifications were general and familiar, so the users would be able to meet the technical } \\
\text { specifications of http://gonusadua.com. }\end{array}$ \\
Economic & $\begin{array}{l}\text { The Cost Benefit ratio was above 1 with some benefits, namely saving operational time and cost, could } \\
\text { generating report and also could reducing errors. }\end{array}$ \\
Legal & $\begin{array}{l}\text { The model and products were already granted for intellectual property rights } \\
\text { Although the new system had many advantages over the old system, its operation was hampered by the } \\
\text { emergence of the COVID-19 }\end{array}$ \\
Schedule & $\begin{array}{l}\text { After revising the schedule because of COVID19, the business process reengineering could be finish on } \\
\text { schedule } \\
\text { Average Score }\end{array}$ \\
\hline
\end{tabular}

Based on the analysis result at each stage of the research framework, it can be seen that the researchers constructed a new tourism e-marketplace system with some improvements in the business model as shown in Figure 4. The government had an important role in the proposed e-marketplace, as data centre owner. Government as provider and owner of proposed e-marketplace could support the SMEs ability by providing a new business process with some benefits such as could saving operational time and cost, generating a report and reducing errors.

\section{CONCLUSION}

Business process re-engineering of tourism e-marketplace can be carried out by some stages, namely: (1) acceptance diagnostic, (2) strategic diagnostic, (3) modeling, (4) implementation, and (5) feasibility study. The research took a case study in Nusa Dua Bali. In terms of government support to SMEs, 
BPR was built the new tourism e-marketplace business model. The new model involved three kinds of role, namely: (1) government, (2) SMEs, and (3) tourists, and also consisted of some activities, such as ecommerce, catalogue, finance, inventory management, collaboration, order fulfilment and customization. The tourism e-marketplace business model implemented as http://gonusadua.com. TELOS feasibility study was done with a final score of 8.3. It can be concluded that the tourism e-marketplace business process model was feasible to develop with many benefits for the government, SMEs, and also the tourist. The new system's benefits were the ability to save operational time and cost, generate reports and reduce errors. Beside had a contribution in built a new model of tourism e-marketplace, the research had also constructed a new tourism e-marketplace system with some improvements on the business model. Some limitations in this research can be summarized as: (1) small sample size on acceptance diagnostic stage and (2) limited only in a small area of tourism in Bali. Thus, some future researches can do (1) take a larger sample size and (2) apply the model in a larger tourism area.

\section{ACKNOWLEDGEMENTS}

Gratitude is dedicated to DRPM Kementerian Riset dan Teknologi/Badan Riset dan Inovasi Nasional Indonesia who has funded this research and LPM Kelurahan Benoa who are willing to guide us in the implementation of research and also Politeknik Negeri Bali which gives full permission and support for this research.

\section{REFERENCES}

[1] K. Cao and Z. Yang, "A study of e-commerce adoption by tourism websites in China," Journal of Destination Marketing \& Management, vol. 5, no.3, pp. 283-289, 2016, doi: 10.1016/j.jdmm.2016.01.005.

[2] I. Crnojevac, J. Gugić, and S. Karlovčan, "eTourism: A comparison of Online and Offline Bookings and the Importance of Hotel Attributes," JIOS, vol. 34, no. 1, pp. 41-54, 2010.

[3] G. Ping, "Analysis the Application of E-business for the Tourism Enterprises Performance Evaluation in China," Energy Procedia, vol. 5, pp. 849-854, 2011, doi: 10.1016/j.egypro.2011.03.150.

[4] C. Li, L. Feng and L. Ma, "Business Process Reengineering for Better Sale of China Lubricant Enterprises," 2013 5th International Conference and Computational Intelligence and Communication Networks, 2013, pp. 635-638, doi: 10.1109/CICN.2013.139.

[5] D. Buhalis, "Progress in information technology and tourism management: 20 years on and 10 years after the Internet-The state of eTourism research," Tourism Management, vol. 29, pp. 609-623, 2008, doi: 10.1016/j.tourman.2008.01.005.

[6] I. Condratov, "E-Tourism: Concept and Evolution,“"ECOFORUM, vol. 2, no.1, pp. 1-10, 2013.

[7] D. Labanauskaite, M. Fioreb, and R Stasysa, "Use of emarketing tools as communication management in the tourism industry," Tourism Management Perspectives, vol. 34, April 2020, doi: 10.1016/j.tmp.2020.100652.

[8] B. Mirza, Murtaza, Vipul, Gupta, C Richard, and Carroll, "E-marketplaces and the future of supply chain management: Opportunities and challenges," Business Process Management Journal, vol. 10, pp. 325-335, 2004, doi: $10.1108 / 14637150410539722$.

[9] P. Brunn, M. Jensen and J. Skovgaard, "E-marketplaces: Crafting a winning strategy," European Management Journal, vol. 20, pp. 286-298, 2002, doi: 10.1016/S0263-2373(02)00045-2.

[10] A. S. Nisafani, A. Wibisono, and M. H. T. Revaldo, "Analyzing the effectiveness of public e-marketplaces for selling apparel products in Indonesia," Procedia Computer Science, vol 124, pp. 274-279, 2017, doi: 10.1016/j.procs.2017.12.156.

[11] W. Bauer and J. Dorn, "Requirements for product-service description at e-marketplaces in the manufacturing domain," Procedia CIRP, vol. 47, pp. 406-411, 2016, doi: 10.1016/j.procir.2016.03.040.

[12] Y. Liu and J. Zhang, "An incentive mechanism designed for e-marketplaces with limited Inventory," Electronic Commerce Research and Applications, vol. 13, pp. 110-127, 2014, doi: 10.1016/j.elerap.2013.11.002.

[13] S. Candra and F. E. Gunawan, "The impact of e-procurement practice in Indonesia government: A preliminary study (The case of electronic procurement service at Bekasi district)," Journal of Physics: Conference Series, vol. 801, 2017, doi: 10.1088/1742-6596/801/1/012023.

[14] L. Ferreira, I. Miranda, R. Simoes, and M. Cruz-Cunha, "GuiMarket specification using the unified modeling language," Procedia Computer Science, vol. 64, pp. 1263-1272, 2015, doi: 10.1016/j.procs.2015.09.241.

[15] K. C. Dewi and N. W. D. Ayuni, "Government Readiness and Strategies in E-marketplace Planning using SWOT Analysis and Technology Readiness Index Model," Journal of Physics: Conference Series, vol. 1569, no. 2, 2020, doi: 10.1088/1742-6596/1569/2/022008.

[16] B. Fitzgerald and C. Murphy, "Business process reengineering: The creation and implementation of a methodology," INFOR: Journal of Information Systems and Operational Research, vol. 34, pp. 3-14, 1996.

[17] D. Kumar and A. Bhatia, "Role of IT in business process reengineering," in International Conference on Recent Trends in Information Systems, Kolkata, 2011, pp. 48-52. 
[18] C. Li, L. Feng and L. Ma, "Business Process Reengineering for Better Sale of China Lubricant Enterprises," 2013 5th International Conference and Computational Intelligence and Communication Networks, 2013, pp. 635-638, doi: 10.1109/CICN.2013.139.

[19] Y. Borgianni, G. Cascini and F. Rotini, "Business process reengineering driven by customer value: A support for undertaking decisions under uncertainty conditions," Computers in Industry, vol. 68, pp. 132-147, April 2015, doi: 10.1016/j.compind.2015.01.001.

[20] D. Kumar and A. Bhatia, "Role of IT in business process reengineering," in 2011 International Conference on Recent Trends in Information Systems, Kolkata, 2011, pp. 48-51.

[21] F. Lampathaki, S. Koussouris, and J. Psarras, "Business Process Reengineering 2013-BPR Lifecycle," Decision Support Systems Laboratory, NTUA, 2013.

[22] F. D. Davis, "Perceived usefulness, perceived ease of use, and user acceptance of information technology," MIS Quarterly, vol. 13, no. 3, pp. 319-340, 1989, doi: 10.2307/249008.

[23] M. J. Alsamydai, "Adaptation of the TAM to the use of mobile banking services," International Review of Management and Business Research, vol. 3, no 4, pp. 2016-2028, 2014.

[24] P. Surendran, "Technology Acceptance Model: A survey of Literature," Internatonal Journal of Business and Social Research, vol, 2, no. 4, pp. 175-178, 2012, doi: 10.18533/ijbsr.v2i4.161.

[25] Gelik, H. Eray and Y. Veysel, "Extending the technology acceptance model for adoption of E-shopping by consumers in Turkey," Journal of Electronic Commerce Research, vol. 12, no. 2, pp. 154, 2011.

[26] I. M. Klopping, and E. McKinney, "Extending the Technology Acceptance Model and the Task-Technology Fit Model to Consumer E-commerce," Information Technology, Learning, and Performance Journal, vol. 22, no.1, p. 35,2004

[27] R. H. Shroff, C. C. Deneen, and E. M. W. Ng, "Analysis of the technology acceptance model in examining students' behavioural intention to use an e-portfolio system," Australasian Journal of Educational Technology, vol. 27, no. 4, pp. 600-618, 2011, doi: 10.14742/ajet.940.

[28] S. Alharbi and S. Drew, "Using the Technology Acceptance Model in Understanding Academics' Behavioural Intention to Use Learning Management Systems," International Journal of Advanced Computer Science and Applications, vol. 5, no. 1, pp. 143-155, 2014, doi: 10.14569/IJACSA.2014.050120.

[29] P. C. Lai, "The Literature Reiew of Technology Adoption Models and Theories for the novelty Technology," Journal of Information Systems and Technology Management, vol. 14, no. 1, pp. 21-38, 2017, doi: 10.4301/s180717752017000100002.

[30] I. Bider and A. Jalali, "Agile Business Process Development: Why, How and When," Journal of Information Systems and e-Business Management, vol. 14, no. 4, pp. 693-731, 2016, doi: 10.1007/s10257-014-0256-1.

[31] A. Schatten and J. Schiefer, "Agile Business Process Management with Sense and Respond," IEEE International Conference on e-Business Engineering (ICEBE'07), 2007, pp. 319-322, doi: 10.1109/ICEBE.2007.43.

[32] A. S. Campanelli and F. S. Parreiras, "Agile Methods Tailoring - A Systematic Literature Review," The Journal of Systems and Software, vol. 110, pp. 85-100, 2015, doi: 10.1016/j.jss.2015.08.035.

[33] I. R. Lima, T. C. Freire and H. A. X. Costa, "Adapting and Using Scrum in a Software Research and Development Laboratory," Revista de Sistemas de Informação da FSMA, vol. 9, pp. 16-23, 2012.

[34] M. Mukherje and S. Roy, "Feasibility Studies and Important Aspect of Project Management," International Journal of Advanced Engineering and Management, vol. 2, no. 4, pp. 98-100, 2017, doi: 10.24999/IJOAEM/02040025.

[35] J. K. Segawaa and M. Muzindab, "Feasibility Assessment Framework (FAF): A Systematic and Objective Approach for Assessing the Viability of a Project," Procedia Computer Science, vol. 181, pp. 377-385, 2021, doi: 10.1016/j.procs.2021.01.180.

[36] K. C. Dewi and N. W. D. Ayuni, "Factors Affecting Acceptance of E-marketplace Based On Hybrid Model of Modified TAM-TRI," 2020 Fifth International Conference on Informatics and Computing (ICIC), 2020, pp. 1-8, doi: 10.1109/ICIC50835.2020.9288626.

[37] A. M. Colley and T. M. Gale, "Effects of gender role identity and experience on computer attitudes," Journal of Educational Computing Research, vol. 10, no. 2, pp. 129-137, 1994, doi: 10.2190/8NA7-DAEY-GM8P-EUN5.

[38] S. Conger and D. K. Loch, "Ethics and information technology use-a factor-analysis of attitudes to computer use," Information Systems Journal, vol. 5, no. 3, pp. 161-183, 1995, doi: 10.1111/j.1365-2575.1995.tb00106.x.

[39] D. McIlroy and D. Bunting, "The relation of gender and background experience to self-reported computing anxieties and cognitions," Computers in Human Behavior, vol. 17, pp. 21-33, 2001, doi: 10.1016/S07475632(00)00037-6

[40] R. G. Saade and D. Kira, "Mediating the impact of technology usage on perceived ease of use by anxiety," Computer and education, vol. 49, pp. 1189-1204, 2007, doi: 10.1016/j.compedu.2006.01.009.

[41] S. Srivastava and T. Teo, "Determinants and impact of e-government and e-business development: A global perspective," in International Conference on Information Systems, Wisconsin, 2006, pp. 365-378.

[42] V. Vijay, K. Durbhakula, and J. Kim, "E-business for Nations: A Study of National Level E-business Adoption Factors Using Country Characteristics-Business-Technology-Government Framework," Journal of Theoretical and Applied Electronic Commerce Research, vol. 6, no. 3, pp. 1-12, 2011, doi: 10.4067/S0718-18762011000300002.

[43] Sfenrianto, T. Wijaya, and G. Wang, "Assessing the Buyer Trust and Satisfaction Factors in the E-Marketplace," Journal of Theoretical and Applied Electronic Commerce Research, vol. 13, no. 2, pp. 43-57, 2018, doi: 10.4067/S0718-18762018000200105.

[44] P. Acheampong, L. Zhiwen, H. A. Antwi, A. A. Otto, W. G. Mensah, and P. B. Sarpong, "Hybridizing an Extended Technology Readiness Index with Technology Accepance Model (TAM) to Predict E-Payment Adoption In Ghana," American Journal of Multidisciplinary Research, vol. 5, no. 2, pp. 172-184, 2017. 
[45] Parasuraman and Ananthanarayanan, "Technology Readiness Index (TRI) a multiple-item scale to measure readiness to embrace new technologies," Journal of service research, vol. 2, no.4, pp. 307-320, 2000, doi: $10.1177 / 109467050024001$.

[46] M. G. Aboelmaged, "Predicting ereadiness at firm-level: An analysis of technological, organizational and environmental (TOE) effects on emaintenance readiness in manufacturing firms," International Journal of Information Management, vol. 34, no.5, pp. 639-651, 2014, doi: 10.1016/j.ijinfomgt.2014.05.002.

[47] R. Shambare, "Technology readiness and EFTPoS usage in Zimbabwe," International Journal of Business and Economic Development (IJBED), vol. 1, no. 1, 2013.

\section{BIOGRAPHIES OF AUTHORS}

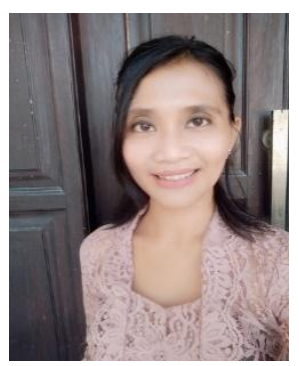

Kadek Cahya Dewi received her Master of Computer Science from Universitas Gadjah Mada in 2010. She is currently an assistant professor at the Department of Business, Politeknik Negeri Bali, Indonesia. Her research is mainly focused on e-business, information systems and artificial inteligence.

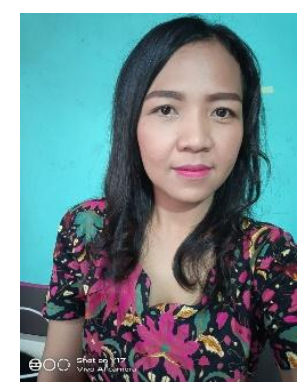

Ni Wayan Dewinta Ayuni received her master of Statistics from Institut Teknologi Sepuluh Nopember Surabaya in 2013. Now she is a lecturer in Accounting department Politeknik Negeri Bali. Her research is mainly focus in statistical modeling. 